\title{
EXPRESSION OF SYNAPTOPHYSIN DURING THE PRENATAL DEVELOPMENT OF THE RAT SPINAL CORD: CORRELATION WITH BASIC DIFFERENTIATION PROCESSES OF NEURONS
}

\author{
M. Bergmann, ${ }^{*}$ G. Lahr, A. Mayerhofer and M. Gratzl $\dagger$ \\ Abteilung Anatomie und Zellbiologie der Universität Ulm, D-7900 Ulm, F.R.G.
}

\begin{abstract}
Ahstract-The development of the spinal cord involves the proliferation of neurons, their migration to well-defined areas, fiber outgrowth and synapse formation. The present study was designed to correlate the spatiotemporal pattern of expression of synaptophysin, an integral membrane protein of small synaptic vesicles, with these basic processes occurring during the embryonic development of the rat spinal cord.

Thoracic segments of spinal cords from embryonic days 12,14,16, 18, 20 and of adult spinal cords were studied. S1 nuclease protection assays and immunoblots revealed minute amounts of specific mRNA and synaptophysin at embryonic day 12 . There was a steep increase of mRNA between embryonic days 14 and 16, after which levels reached a plateau. A rise in the amount of synaptophysin in the spinal cord occurred between embryonic days 12 and 14, and the levels changed only slightly until the end of embryonic development. Even higher levels of synaptophysin, found in the adult spinal cord, may indicate that its biosynthesis continued after birth.

In situ hybridization histochemistry revealed the localization of specific synaptophysin mRNA in the neuroepithelium. However, immunocytochemistry failed to detect synaptophysin in the neuroepithelial cells. Following migration of the neuroblasts, synaptophysin was found in neurons concomitantly with the onset of fiber outgrowth. Thus, already at embryonic day 12, outgrowing fibers of the dorsal root sensory neurons and of motoneurons were synaptophysin positive. From embryonic day 14 throughout the prenatal period, strong synaptophysin immunoreactivity was seen in the ventrolateral and dorsal parts of the marginal layer. Most likely this staining pattern indicates transient functional synaptic contacts because, in the adult spinal cord, the corresponding region, the white matter, exhibited only faint synaptophysin immunoreactivity. In the intermediate layer of the embryonic spinal cord, which corresponds to the gray matter of the adult spinal cord, synaptophysin-positive fibers were observed prior to the formation of functional synapses. The latter are most likely permanent, since synaptophysin in the adult spinal cord is mainly confined to the gray matter.

Our data (i) show transcription and translation of synaptophysin within the neurons of the spinal cord and correlate these processes with proliferation, migration, fiber outgrowth and the formation of transient or permanent synapses, and (ii) prove that synaptophysin is a marker for fiber outgrowth in addition to synapse formation.
\end{abstract}

The developing spinal cord represents an area of the central nervous system in which cell replication and cell migration have been well examined. ${ }^{1}$ In contrast, details of further differentiation during neurogenesis including fiber outgrowth and formation of mature (functional) synapses have been studied far less. One prerequisite of neuronal signalling is the storage and release of neurotransmitters from synaptic vesicles. The synaptic vesicle membranes are known to contain several unique proteins. Synaptophysin, the most abundant one, is well characterized in its biochemical and molecular properties. ${ }^{9,11,16,32,33}$ In some areas of

*Present address: Institut für Anatomie, Charité, Humboldt-Universität, Berlin.

$\uparrow$ To whom correspondence should be addressed at: Abteilung Anatomie und Zellbiologie der Universität, Albert-Einstein-Allee 11, D-7900 Ulm, F.R.G.

Abbreviations: ABC, avidin-biotin-peroxidase complex; ED, embryonic day; EDTA, ethylene diaminetetra-acetate; IgG, immunoglobulin G; PBS, phosphate buffered saline; PIPES, 1,4-piperazine diethane sulfonic acid; SSC, sodium chloride/sodium citrate; S1, S1 nuclease. the central nervous system ${ }^{7,14}$ the formation of synapses and the expression of synaptophysin occurs simultaneously, suggesting that synaptophysin is a marker for synaptogenesis. With this in view we investigated the expression of synaptophysin in the developing spinal cord at protein and mRNA levels.

\section{EXPERIMENTAL PROCEDURES}

\section{Animals}

Adult and pregnant female rats (Sprague-Dawley) were purchased from Charles River (Sulzfeld, F.R.G.). The day after mating was defined as embryonic day 1 (ED 1). Embryonic material was obtained from the 12th to the 20th day of gestation (ED 12-20).

\section{Immunohistochemistry and immunoblotting}

Embryos of ED 12 and 14 were fixed by immersion in 4\% paraformaldehyde in $0.1 \mathrm{M}$ phosphate buffer $(\mathrm{pH} 7.4)$ for $6 \mathrm{~h}$ at $4^{\circ} \mathrm{C}$, while embryos of ED $16-20$ were fixed by intracardiac perfusion using the same fixative. The thoracic segments of the spinal cord were dissected and immersed overnight in a $20 \%$ sucrose in $0.1 \mathrm{M}$ phosphate buffer at $4^{\circ} \mathrm{C}$. Transverse sections $(10$ or $20 \mu \mathrm{m})$ were cut on a cryostat (Reichert) and mounted onto gelatin-coated glass 
slides. For immunocytochemical visualization of synaptophysin, a polyclonal rabbit antiserum directed against rat synaptophysin (see Refs 10, 11; kindly provided by $\operatorname{Dr} R$. Jahn, Martinsried) and the avidin-biotin-peroxidase complex (ABC) technique ${ }^{8}$ was used. Endogenous peroxidase activity was blocked with $0.03 \% \mathrm{H}_{2} \mathrm{O}_{2}$ and $10 \%$ methanol in phosphate-buffered saline (PBS). The sections were incubated for $12-20 \mathrm{~h}$ at $4^{\circ} \mathrm{C}$ with a 1:8000 dilution of the primary antiserum in PBS containing also $0.5 \%$ bovine serum albumin and $0.05 \%$ sodium azide. Biotinylated antirabbit immunoglobulin (IgG) (diluted 1:500, from Vector, Burlingame, CA, U.S.A.) and ABC (diluted 1:200, Vector, Burlingame, CA, U.S.A.) were used in the second and third steps of the immunostaining. Both incubations were carried out for $2 \mathrm{~h}$ at room temperature. The immunoreaction was visualized by a freshly prepared solution of $0.05 \%$ 3,3'diaminobenzidine-tetrahydrochloride (Aldrich, Milwaukee, WI, U.S.A.) and $0.01 \% \mathrm{H}_{2} \mathrm{O}_{2}$ in $0.05 \mathrm{M}$ Tris-HCl buffer ( $\mathrm{pH} \mathrm{7.6)}$ for $10 \mathrm{~min}$. Controls were incubated with $2 \%$ normal swine serum in PBS. Sections were photographed using a Zeiss photomicroscope. We used the established nomenclature of Altman and Bayer ${ }^{1}$ to describe the immunocytochemical as well as autoradiographic histochemical results.

For immunoblotting, spinal cords (ED 12 and 14; ED 16-20, thoracic segments) were removed from the embryos and homogenized in a Teflon-to-glass homogenizer followed by sonication. After sodium dodecyl sulfate-polyacrylamide gel electrophoresis and blotting to nitrocellulose, immunoreactive bands were visualized with the same synaptophysin antiserum used for immunocytochemistry at a dilution of 1:8000 by autoradiography using iodinated protein $A$. The method has been described previously in detail. ${ }^{30}$

\section{$c D N A$ and $c R N A$ probes}

The rat synaptophysin cDNA (kindly provided by $\mathrm{Dr} \mathrm{H}$. Betz, Frankfurt, F.R.G) has been previously characterized. ${ }^{16}$ In brief, the 971 bp cDNA of the protein coding region of rat synaptophysin was cloned via synthetic adapters into the EcoRI site of the Bluescript M13 (t), KS-vector (Stratagene, La Jolla, CA, U.S.A.) in both orientations. These clones referred to as P38/S41 M13 (+) and P38/S42 M13 (t) were used to generate cRNA (P38/S41) and cDNA (P38/S42) antisense strands of the rat synaptophysin mRNA.

For S1 nuclease (SI) analysis, single stranded DNA was isolated after infection of the bacterial strain CMK603, containing the P38/S42 M13(+) plasmid, with the helper phage $\mathrm{f} 1$, according to the protocol of Promega Biotec (Madison, WI, U.S.A.). Uniformly labeled single-stranded cDNA probe was prepared as previously described. ${ }^{17.27}$ The labeled primer extended P38/S42 M13(+) subclone was digested with PvuII, yielding three fragments, which were separated on $5 \%$ polyacrylamide gels $(8.3 \mathrm{M}$ urea); the 1055-nucleotide fragment was isolated and re-run on a $1 \%$ agarose gel. The DNA fragment was then transferred electrophoretically to a NA45 DEAE-cellulose membrane (Schleicher \& Schüll, F.R.G.) and eluted from the filter as described previously. ${ }^{18}$

The 1055-nucleotide fragment yielded was used for the $\mathrm{S} 1$ assay. This cDNA probe contains 905 -nucleotide of the translated part of the sequence initiating at the $5^{\prime}$ end of the rat synaptophysin sequence, extending into 39-nucleotide of the $3^{\prime}$ untranslated part of the sequence, and 111-nucleotide of vector sequences (see Fig. 2A).

Synthesis of ${ }^{35} \mathrm{~S}$-labeled cRNA (spec. act. $4 \times 10^{8}$ c.p.m. $/ \mu \mathrm{g}$ ) for in situ hybridization was carried out according to the T3-polymerase protocol of Promega Biotec (Madison, WI, U.S.A.) using $10^{7} \mu \mathrm{Ci}$ of $\alpha-\left[{ }^{35} \mathrm{~S}\right] \mathrm{CTP}$ (spec. act. $37 \mathrm{TBq} / \mathrm{mMol}$ ) and P38/S41 $\mathrm{Ml} 3(+)$ linearized with HinfI. The resulting cRNA probe contained 142-nucleotide of the $3^{\prime}$ end and 39-nucleotide of the $3^{\prime}$ untranslated sequence of the rat synaptophysin gene and 70-nucleotide of vector sequences (see Fig. 2A)). For the synthesis of the control sense RNA (spec. act. $2.5 \times 10^{4}$ c.p.m. $/ \mu$ g) we used clone $\mathrm{p} 38 / \mathrm{S} 42 \mathrm{M} 13(+)$ linearized with HinfI. The resultant sense cRNA probe contained 21 -nucleotide of the $5^{\prime}$ end and 70 -nucleotide of vector sequences.

\section{$S 1$ nuclease protection assay}

Total RNA was isolated by a modified guanidinium thiocyanate-CsCl method ${ }^{13}$ from extracted thoracic embryonic spinal cord at different embryonic stages and adult animals from pooled male and female rats.

Twenty micrograms total RNA (determined photometrically) was hybridized with an excess of ${ }^{32} \mathrm{P}$-labeled cDNA probe $\left(5 \times 10^{4}\right.$ c.p.m.; spec. act. $1 \times 10^{8}$ c.p.m. $\left./ \mu \mathrm{g}\right)$ in $75 \%$ formamide, $400 \mathrm{mM} \mathrm{NaCl}, 1 \mathrm{mM} \mathrm{EDTA}$ and $20 \mathrm{mM}$ Tris- $\mathrm{HCl}(\mathrm{pH} 7.4)^{27}$ for $16 \mathrm{~h}$ at $58^{\circ} \mathrm{C}$. Hybridization was terminated by digestion with $680 \mathrm{U}$ S1 nuclease (S1) (AGS, Heidelberg, F.R.G.) for $2 \mathrm{~h}$ at $37^{\circ} \mathrm{C}$. After phenol extraction and ethanol precipitation, samples were separated electrophoretically on $0.3-$ mm-thick $5 \%$ polyacrylamide gels (8.3 $\mathrm{M}$ urea). Gels were dried and exposed on X-ray film at $-70^{\circ} \mathrm{C}$ using intensifying screens. The densitometric evaluation of the gels (as well as of the immunoblots) was carried out with a video-adapted image analysis program based on a PFG-PLUS-512 board (Imaging Technology, Woborn, MA, U.S.A.) developed by W. Warchol.

In situ hybridization histochemistry

Tissues were immediately immersed in Bouin's fixative for $12 \mathrm{~h}$. Subsequently they were embedded in paraffin and serial sections were cut $(5 \mu \mathrm{m})$ and mounted on 3aminopropyl-triethoxysilan (Sigma)-coated slides.

The sections were deparaffinized by running through xylene and ethanol, chloroform and ethanol, they were dried under vacuum and prehybridized at $50^{\circ} \mathrm{C}$ for $3 \mathrm{~h}$ with $1 \mathrm{ml}$ hybridization solution $[50 \%$ formamide, $0.75 \mathrm{M} \mathrm{NaCl}$, 25 mM PIPES, pH 6.8; 25 mM EDTA; $5 \times$ Denhardt's; $0.2 \%$ sodium dodecyl sulfate; $10 \mathrm{mM}$ DTT; $250 \mu \mathrm{g} / \mathrm{ml}$ denaturated herring sperm DNA (Boehringer, Mannheim, F.R.G.); $250 \mu \mathrm{g} / \mathrm{ml}$ yeast tRNA (Boehringer, Mannheim, F.R.G.) and $10 \%$ dextran sulfate]. Subsequently they were hybridized at $50^{\circ} \mathrm{C}$ overnight with $5 \mathrm{ng}$ labeled cRNA probe (spec. act. $4 \times 10^{8}$ c.p.m. $/ \mu \mathrm{g}$ ) in $150 \mu \mathrm{l}$ hybridization solution in a humified chamber. Controls consisted of sections pretreated with $100 \mu \mathrm{g} / \mathrm{ml}$ RNAse A (Boehringer) at $37^{\circ} \mathrm{C}$ for $30 \mathrm{~min}$ prior to hybridization and by use of $5 \mathrm{ng}$ labeled sense cRNA probe (spec. act. $2.5 \times 10^{8}$ c.p.m. $/ \mu \mathrm{g}$ ) in $150 \mu \mathrm{l}$ hybridization solution. After hybridization, sections were rinsed twice in $4 \times$ sodium chloride/sodium citrate (SSC), $20 \mathrm{mM} \beta$-mercaptoethanol and twice in $4 \times \mathrm{SSC}$ at room temperature. In order to reduce background, sections were treated for $30 \mathrm{~min}$ at $37^{\circ} \mathrm{C}$ in a buffer containing $0.5 \mathrm{M}$ $\mathrm{NaCl}, 10 \mathrm{mM}$ Tris- $\mathrm{HCl} \mathrm{pH} 7.5,1 \mathrm{mM}$ EDTA and $100 \mu \mathrm{g} / \mathrm{ml}$ RNAse $A$. They were then incubated for $30 \mathrm{~min}$ at $37^{\circ} \mathrm{C}$ in the same buffer without RNAse $\mathrm{A}$ added and washed twice with $2 \times$ SSC at $50^{\circ} \mathrm{C}$ for $15 \mathrm{~min}$. Slides were rinsed in ascending alcohol solutions, air-dried and dipped in Ilford $\mathrm{K} 2$ emulsion diluted $1: 1$ with $\mathrm{H}_{2} \mathrm{O}$. They were exposed for four weeks at $4^{\circ} \mathrm{C}$ and developed with Kodak D19 at $16^{\circ} \mathrm{C}$ for $4 \mathrm{~min}$. The sections were counterstained with Hemalaun (Mayer) and eosin.

\section{RESULTS}

In an attempt to analyse the time-course of synaptophysin expression in the rat spinal cord, we first determined the amounts of synaptophysin mRNA and of synaptophysin in spinal cord extracts at different embryonic days. At ED 12 only minute amounts of synaptophysin and its mRNA could be detected in immunoblots and $S 1$ nuclease analyses, respectively (Figs 1, 2). Between ED 12 and 14 both 


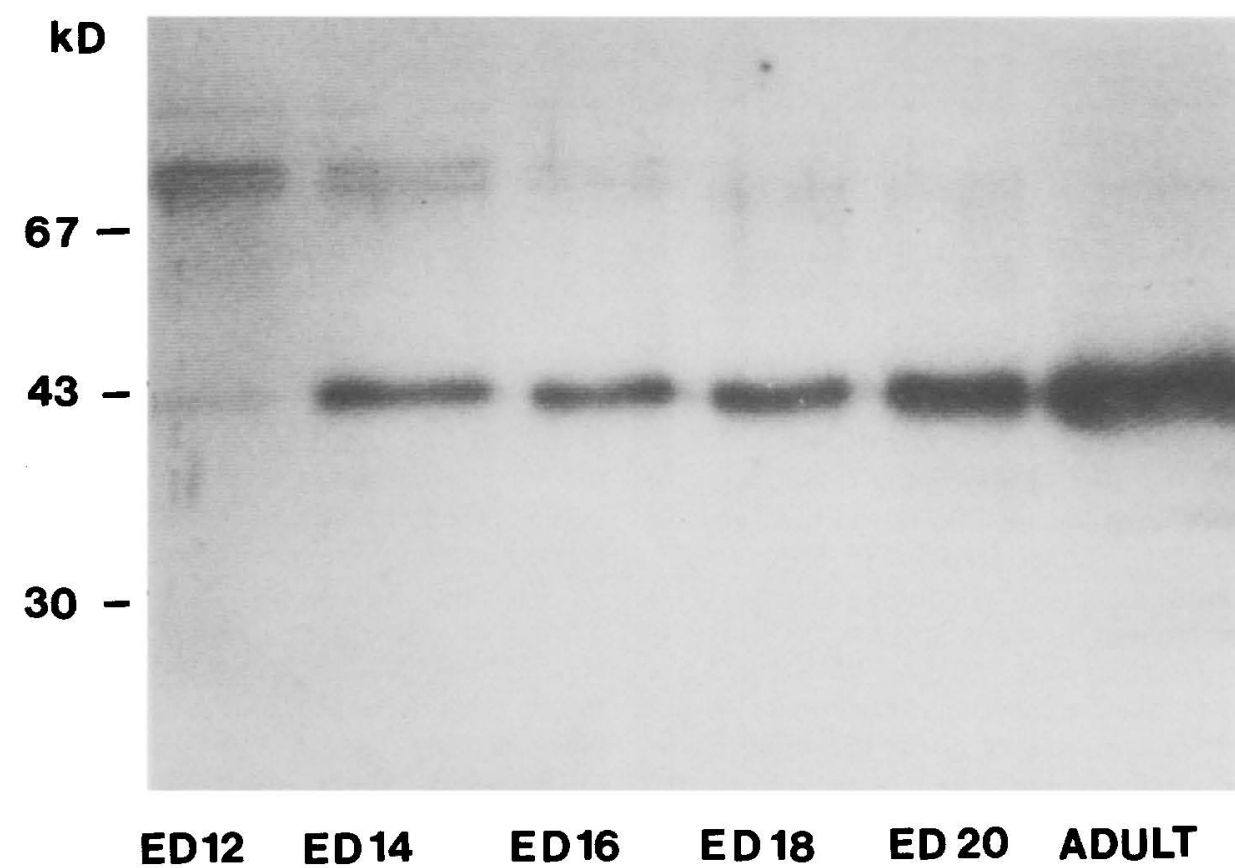

Fig. 1. Western blot of synaptophysin in embryonic and adult rat spinal cords. Synaptophysin increases between ED 12 and 20 approaching the adult level (see also Fig. 3). At ED 12, 14 and 16 an additional immunoreactive band with a molecular weight of around 67,000 is visible. Fifteen micrograms of protein loaded per slot. The sizes of the molecular weight markers are indicated on the left side.

synaptophysin and its mRNA increased. The amount of synaptophysin reached a plateau between ED 14 and 18 followed by a moderate increase prior to birth. However, the level of synaptophysin at ED 20 was lower than that observed in the adult rat. At ED 12, when synaptophysin itself exhibited only a very weak band (see Fig. 1), an additional immunoreactive doublet of bands at approximately $67,000 \mathrm{~mol}$. wt was prominent. This doublet gradually decreased between ED 14 and 18. The time-course of expression of synaptophysin mRNA was different to that of the protein. A steep increase in synaptophysin mRNA was observed between ED 14 and 16. Then a high level of specific mRNA was maintained throughout the embryonic period (Fig. 3).

In situ hybridization histochemistry and immunocytochemistry were used to identify the neurons of the spinal cord engaged in transcription and translation of synaptophysin (Figs 4-8). At ED 12 and 14 transcription occurred in the neuroepithelium (Fig. $4 \mathrm{~A}, \mathrm{~B})$, as well as in neurons, which had migrated. This is shown for ED 14 in Fig. 4A, B, where synaptophysin mRNA was found in the motor neurons of the ventral horn and in the neurons of the lateral horn. In addition, the dorsal root ganglion exhibited strong labeling. No specific labeling could be detected with the sense cRNA (Fig. 4C) or after treatment with RNAse A prior to hybridization (not shown).

The in situ hybridization data support the observations obtained by immunocytochemistry. At ED 12 , when the neural tube consists of the neuroepithelium and the primitive ventral horn, faint synapto- physin immunoreactivity could be observed in the motor neurons of the ventral horn (Figs 5A, 6C). Immunoreactivity was more pronounced at its external border as well as in the outgrowing nerve fibers of the motoneurons of the ventral horn (Fig. 6C). A faint staining was also seen in the dorsal root ganglion (Figs 5A, 6A). Its fibers approaching the immature dorsal horn exhibit stronger immunoreactivity (see the higher magnification of the dorsal root and the dorsal root entrance zone in Fig. 6A). In contrast to the postmitotic neurons described above, the proliferating cells within the neuroepithelium were unstained at ED 12 as well as in all later stages (see Fig. 5A, B). Also, the ependymal cell layer surrounding the central canal was immunonegative for synaptophysin in all sections studied (Fig. 5A, B).

Faint synaptophysin immunoreactivity in the perikarya and increased staining in the more peripheral parts of the nerve fibers were also a consistent observation at ED 14. This could be observed in the region of the contralaterally projecting fibers of the ventral commissure, as well as in the region of the ipsilaterally projecting fibers of the interneurons (Fig. 5A). However, at ED 14 most prominent immunostaining occurred at two places, namely within the bifurcation zone of the dorsal root and in the ventral funiculus of the marginal layer (Figs 5A, 6B, D). The latter was interrupted by faintly stained channels, which contain fibers of the motoneurons leaving the spinal cord (see Figs 5, 6D, 7). The staining of these fibers became stronger with increasing distance from the perikarya (Fig. 7) 
At ED 16-20, synaptophysin immunoreactivity was mainly confined to the ventral marginal layer (Fig. 5A, B). Its ventral funiculus becomes continuous with the newly formed lateral funiculus (outgrowth of the ipsilaterally projecting fibers of the relay neurons) (Fig. 5A). In addition, the dorsal funiculus exhibited synaptophysin immunoreactivity due to the growth of the intrasegmental primary afferent colaterals to the dorsal horn at ED 16 (Figs $5 A, 8)$. At ED 18, within the dorsal spinal cord, the dorsal funiculus ascending zone is formed, which exhibited strong immunoreaction (Fig. 5B). At ED 20 the strongly stained dorsal funiculus could clearly be distinguished from the adjacent dorsal horn and the posterior sulcus becomes deeper (Fig. 5B).

In the adult spinal cord, synaptophysin immunoreactivity occurred in the entire gray matter, especially in the superficial layers (L I-III) of the dorsal horn. Staining was weak or absent in the perikarya, but punctuate staining was obvious, indicating, most likely, surrounding nerve terminals. In contrast, the white matter exhibited only faint staining (Fig. 5B).

\section{DISCUSSION}

There are two principal novel findings concerning the expression of synaptophysin during the ontogeny of the spinal cord: Its mRNA is already present in the neuroepithelium, but the protein synaptophysin is not present before postmitotic neurons have migrated. Furthermore, synaptophysin is disposed in outgrowing nerve fibers and is not restricted to synapses.

\section{Synaptophysin transcription and translation precedes synapse formation}

Proliferation of neurons in the developing spinal cord exclusively occurs in the neuroepithelium of the neural tube, giving rise to cells which differentiate into mature neurons. ${ }^{1}$ We observed that synaptophysin mRNA was already present in the neuro- epithelium which was devoid of synaptophysin immunoreactivity. The protein synaptophysin was only expressed in postmitotic cells: e.g. neurons which have migrated and formed the primitive ventral horn at ED 12. This suggests that expression of synaptophysin is under post-transcriptional control. Recently a similar delay between the appearance of specific mRNA and the immunocytochemically detectable protein has been observed in the mitral cells of the olfactory system for a cell surface protein..$^{38}$

In the motor neurons of the ventral horn at ED 12, fiber outgrowth and the expression of synaptophysin, the integral membrane protein of small synaptic vesicles occurred in a parallel way. Moreover, choline acetyltransferase, an important enzyme for transmitter biosynthesis, is present within motor neurons when their axons have projected from the spinal cord..$^{25}$ Thus, the biosynthesis of two prerequisites for future synaptic transmission at the neuromuscular junctions starts as early as ED 12 .

The synaptophysin-containing nerve fibers spread out between ED 12 and 14. The outgrowing fibers are known to reach the myotomes as early as ED $13 .{ }^{1}$ Moreover, although a direct comparison between two species cannot be made, neuromuscular junctions containing a synaptic vesicle antigen have been observed at ED 14 in another rodent species, the mouse. ${ }^{19}$ In the rat, the motor neurons become excitable around ED $14^{28}$ and electrical as well as chemical excitability appear one week before birth. ${ }^{20}$ The first evidence for functional synaptic transmission within rat intercostal muscles was reported to occur at ED 15:6 i.e. three days after the onset of synaptophysin translation.

Pattern of synaptophysin expression during development indicates transient synaptic contacts

At ED 14, synaptophysin within the spinal cord was mainly observed in the marginal layer. It appeared first in the developing ventral funiculus, followed by the lateral (ED 16) and the doral funiculus

Fig. 2. S1 protection analysis of extracted mRNA of rat tissues. For hybridization, a single-stranded anti-sense DNA probe for synaptophysin derived from P38/S42 M13(+) clone, which is an EcoRI subclone of 1055 nucleotides (nt) (see Experimental Procedures), was used. (A) Localization of the single-stranded cDNA probe relative to the $5^{\prime}$ end of synaptophysin. Restriction sites are indicated. Bold numbers below the restriction sites mark the positions of synaptophysin nucleotide sequence ${ }^{16}$ The bold line corresponds to the translated part of the synaptophysin transcript initiating near the $5^{\prime}$ end $(905$ nucleotides), while the thin line ( 39 nucleotides) corresponds to the $3^{\prime}$ untranslated sequence up to the internal EcoRI restriction site. Bluescript $M 13(+)$ vector sequences are indicted as well as the universal M13 primer binding site. The cDNA probe synthesized (see Experimental Procedures) and the fragment protected from S1 digestion are indicated. All sizes of fragments are given above the lines with the exception of the nucleotides corresponding to the cRNA probe. The in vitro run-off transcription start site for synthesis of the cRNA probe is indicated by the T3 promoter. For the run-off transcription the template was digested with Hinf I. The length and the relative position of the cRNA probe synthesized (see Experimental Procedures) is indicated. (B) ${ }^{32} \mathrm{P}$-labeled cDNA probe defined in A served as a hybridization probe for $20 \mu \mathrm{g}$ total RNA each. Extracted RNA of various EDs and of the adult spinal cord are indicated at the bottom lane. As a size marker, HpaII-digested pBR322 was applied to the right. The sizes are indicated on the right side. The 1055 nucleotide band represents undigested cDNA probe (Pr) containing flanking Bluescript $\mathrm{M} 13(+)$ vector sequences, while the 944 nucleotide fragment (arrowhead) indicates from S1 digestion protected synaptophysin mRNA sequences in the tissues analysed. Duration of film exposure was three days. 
A
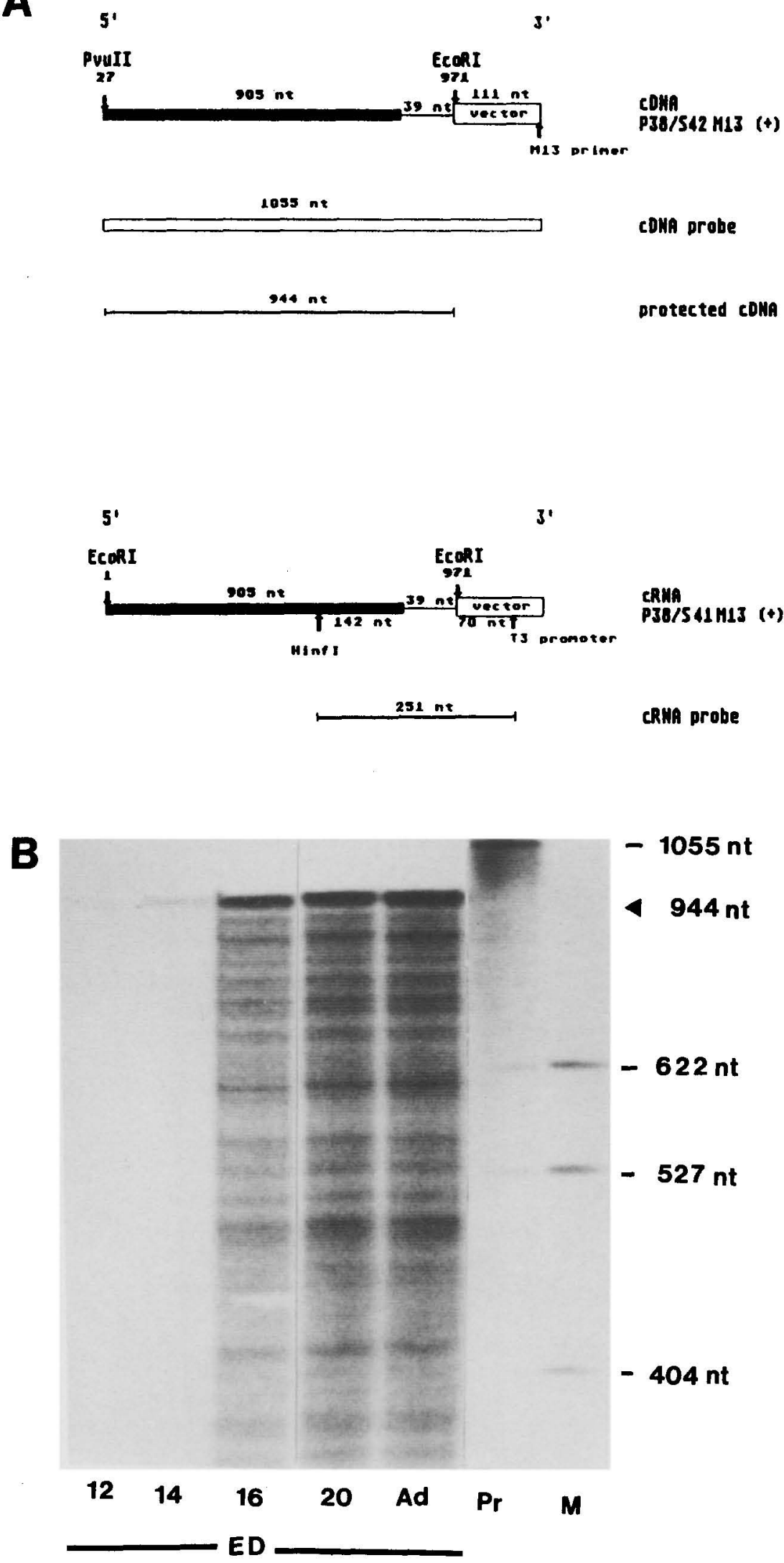

Fig. 2. 
Increase of synaptophysin and its mRNA in the developing rat epinal cord

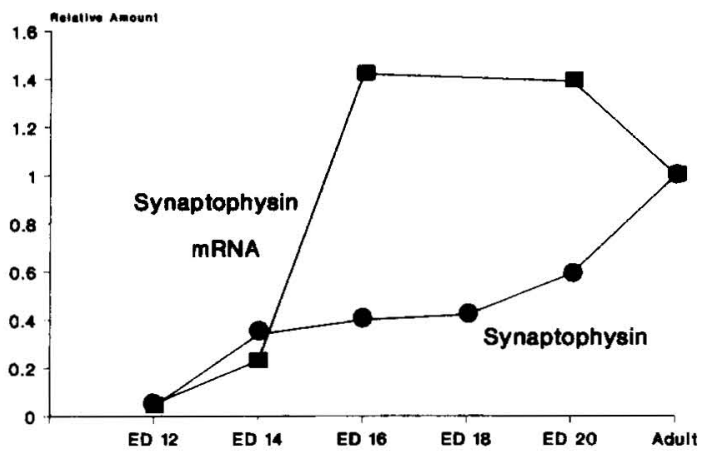

Fig. 3. Densitometric evaluation of synaptophysin and its mRNA in the developing and the adult spinal cord. The autoradiographs of the S1 protection assay (Fig. 2B) and of the immunoblot (Fig. 1) were densiometrically scanned using a video-adapted computer system (see Experimental Procedures). The relative values of gray levels of the bands were plotted on the vertical axis. The values of the adult were arbitrarily set to 1 . Squares equal the relative amount of synaptophysin mRNA synthesized. Circles give the relative amount of translated synaptophysin.
(ED 16) of the marginal layer and was present until ED 20. This distribution is almost a mirror image of the adult spinal cord, where synaptophysin is confined to the gray matter, while the white matter is largely unstained. The preferential location of synaptophysin in the gray matter of the adult animal has also been observed by other investigators. ${ }^{3,4,26}$ This radical difference in the expression of synaptophysin between embryonic and adult animal could be due to breakdown of synaptic contacts in the marginal layer and their formation in the intermediate layer during development of the white and gray matter. A similar reorganization has been observed in the cerebral cortex, in which immunostaining for another synaptic vesicle antigen was found to be transiently present in the area which becomes the white matter in the adult. ${ }^{5}$

The synaptophysin-positive ventrolateral parts of the marginal layer consist of an extensive network of dendritic branches of the motor neurons and axons of the contralaterally and ipsilaterally projecting interneurons. ${ }^{22} 24,34$ In this area, also, a growth conespecific protein (SCG 10) is transiently expressed around ED 14.5-16.5.1 However, as opposed

Abbreviations used in figures

cpf contralaterally projecting nerve fibers

df dorsal funiculus

dfa dorsal funiculus ascending zone

DG dorsal root ganglion

DH dorsal horn

$\mathrm{dr}$ dorsal root

drb dorsal root bifurcation zone

dre dorsal root entrance zone

ic intrasegmental primary afferent colaterals ipc ipsilaterally projecting cells

if lateral funiculus

LH lateral horn

ML marginal layer

ne neuroepithelium

sg sympathetic ganglion

vf ventral funiculus

VH ventral horn

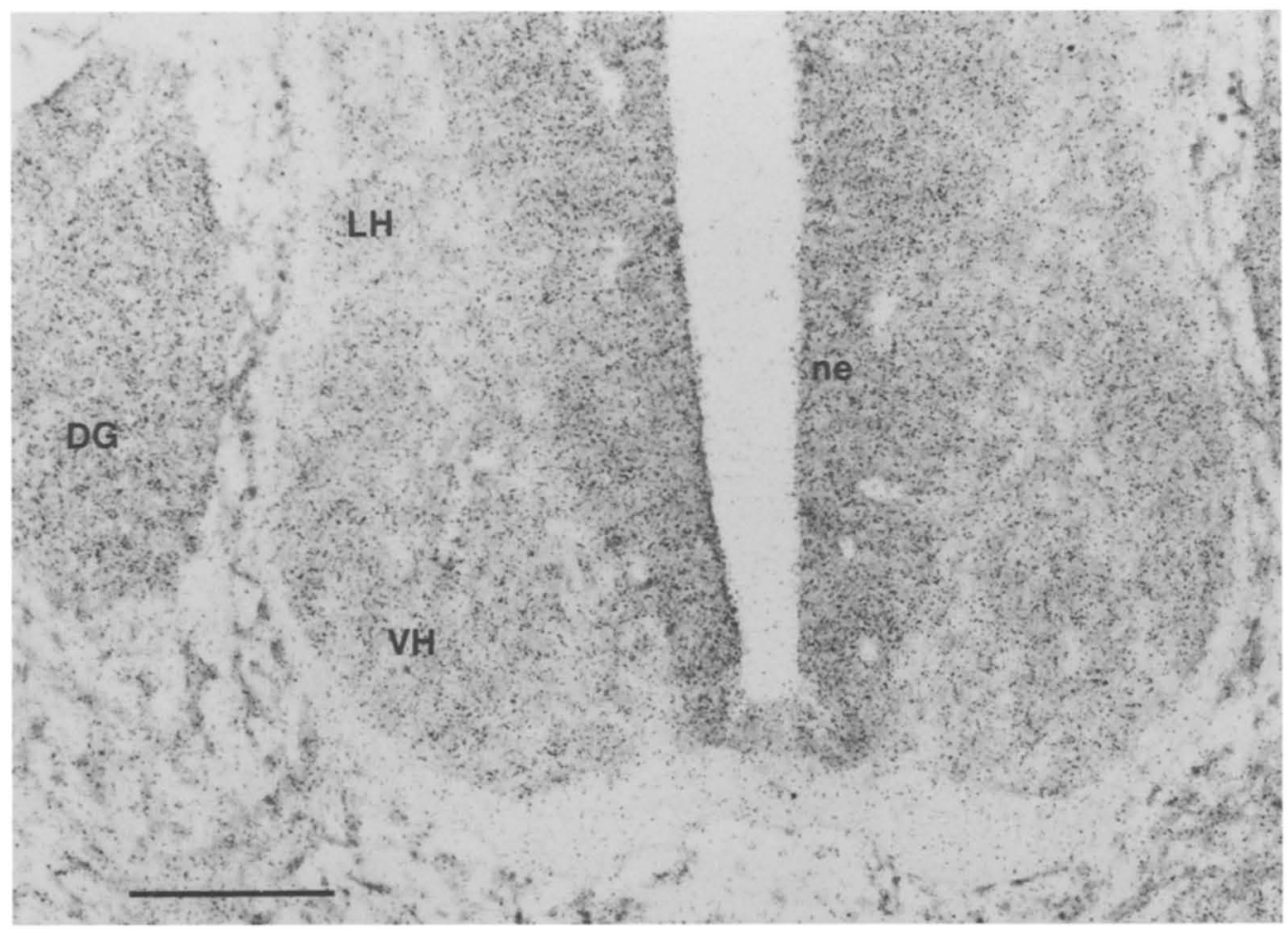

Fig. 4A. 


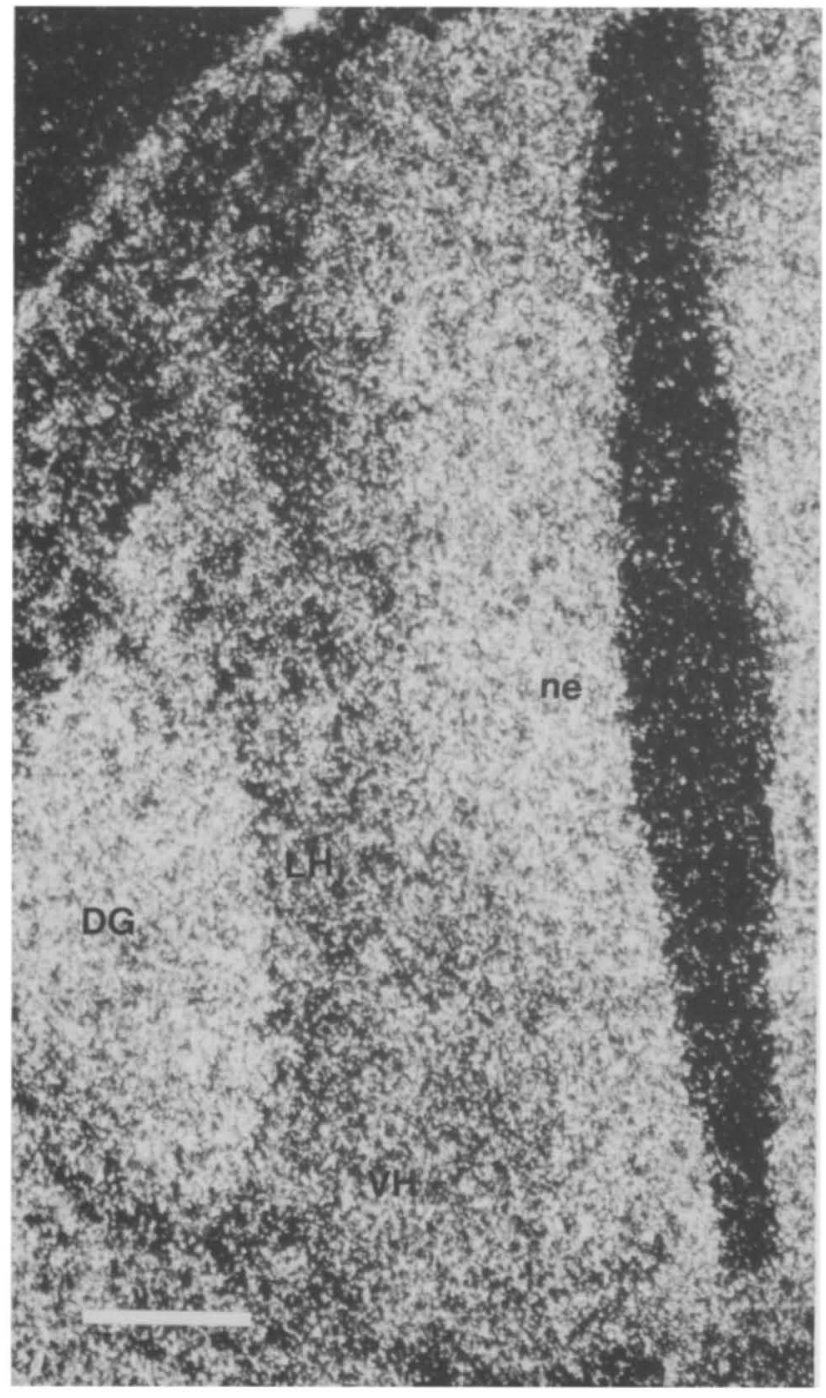

Fig. 4B.

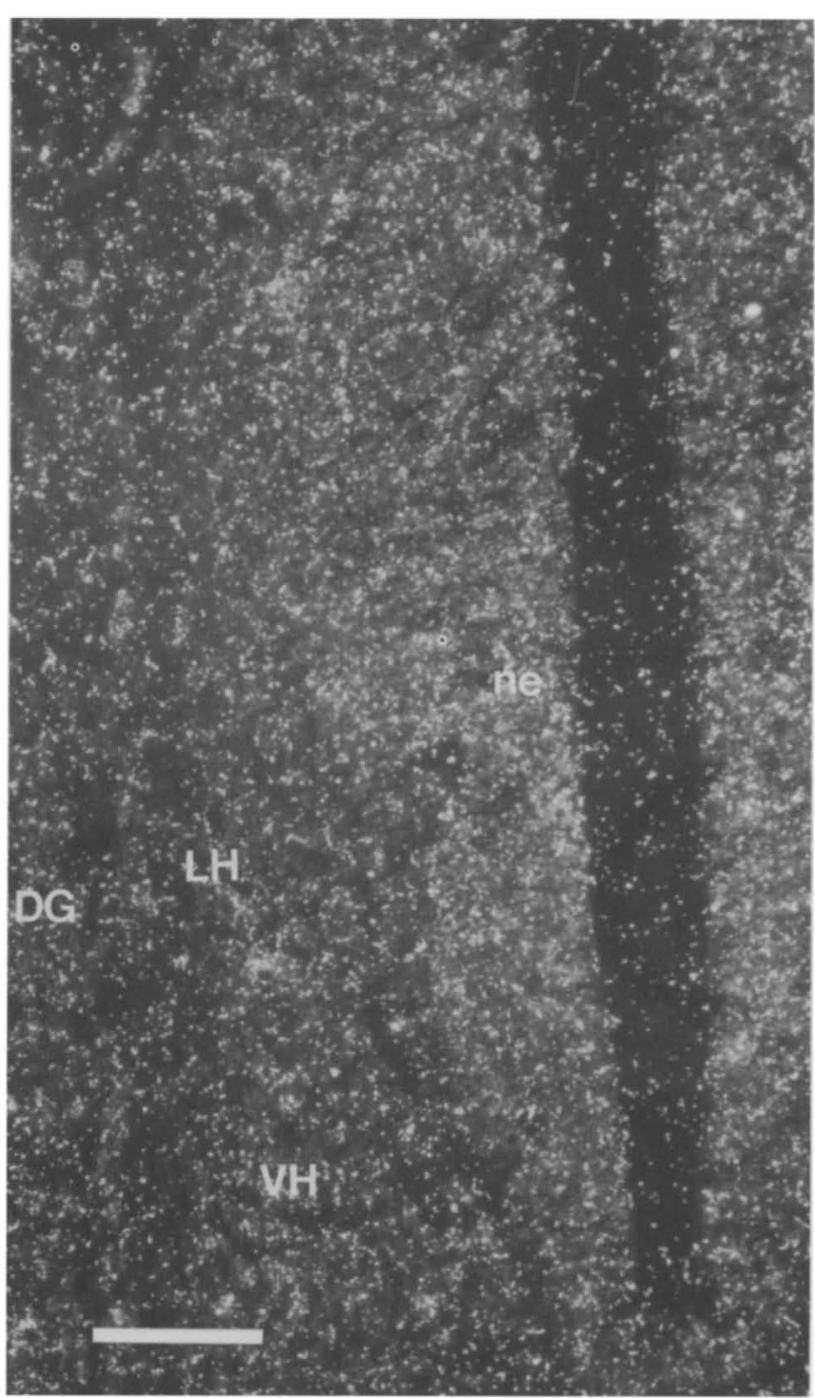

Fig. 4C.

Fig. 4. In situ hybridization histochemistry of the transverse sections of a rat spinal cord (ED 14). (A) Bright-field. Expression of synaptophysin mRNA in the dorsal root ganglion (DG), the ventral horn (VH), the lateral horn (LH) and the neuroepithelium (ne). Scale bar $=125 \mu \mathrm{m}$. (B) Dark-field. Scale bar $=80 \mu \mathrm{m}$. (C) Control with sense RNA. Scale bar $=80 \mu \mathrm{m}$ 
to synaptophysin, this protein is neither expressed in the late prenatal period nor in the adult spinal cord. Interestingly, the time-course of SCG 10 resembles that of the $67,000 \mathrm{~mol}$. wt band cross-reacting with the synaptophysin antibody used in this study. It is presently unknown whether this band corresponds to a stable synaptophysin dimer.

Sophisticated electrophysiological studies of the developing rat spinal cord indicate functional axodendritic synapses (between motor neurons and inter-
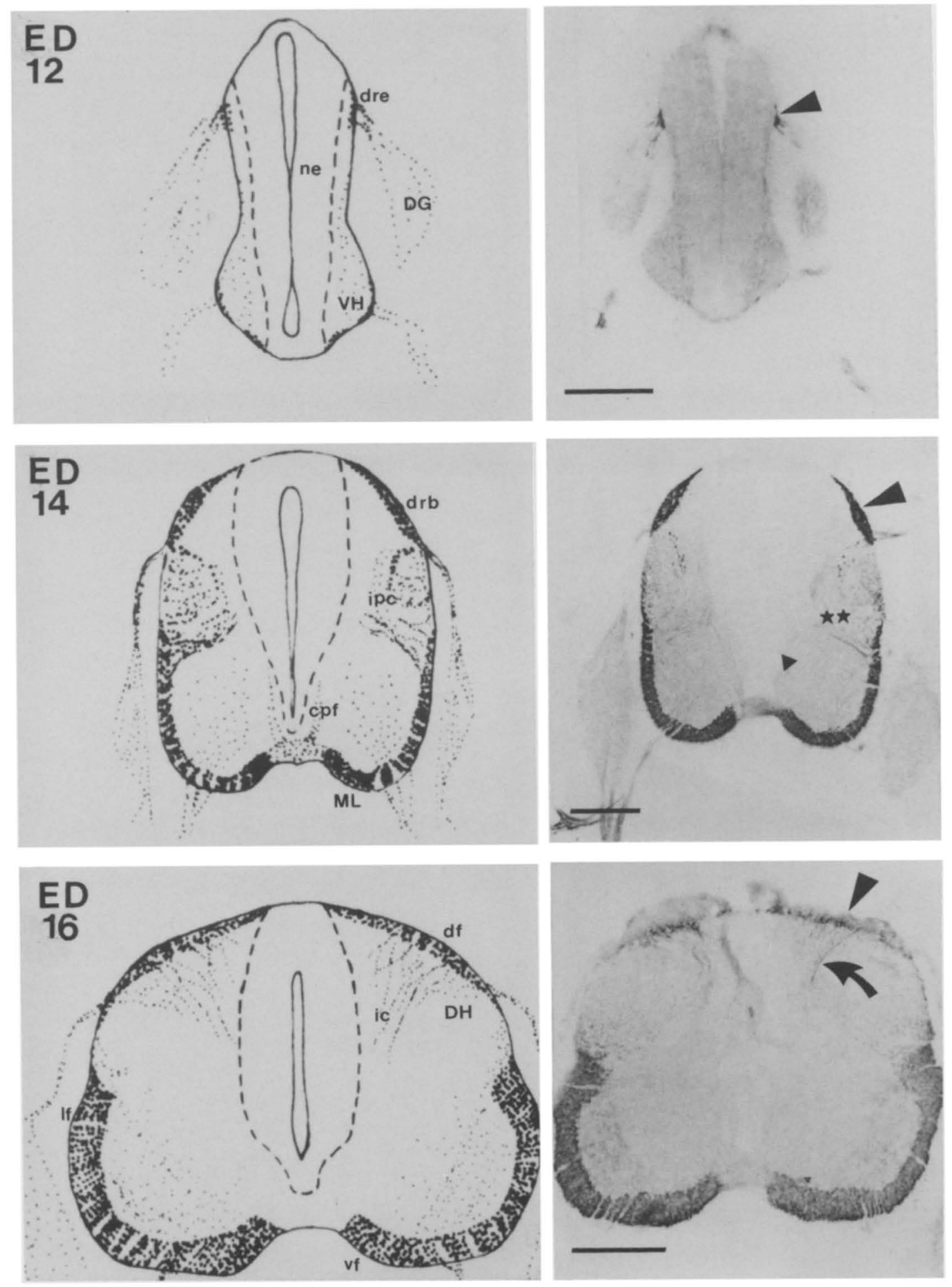

Fig. 5A. 

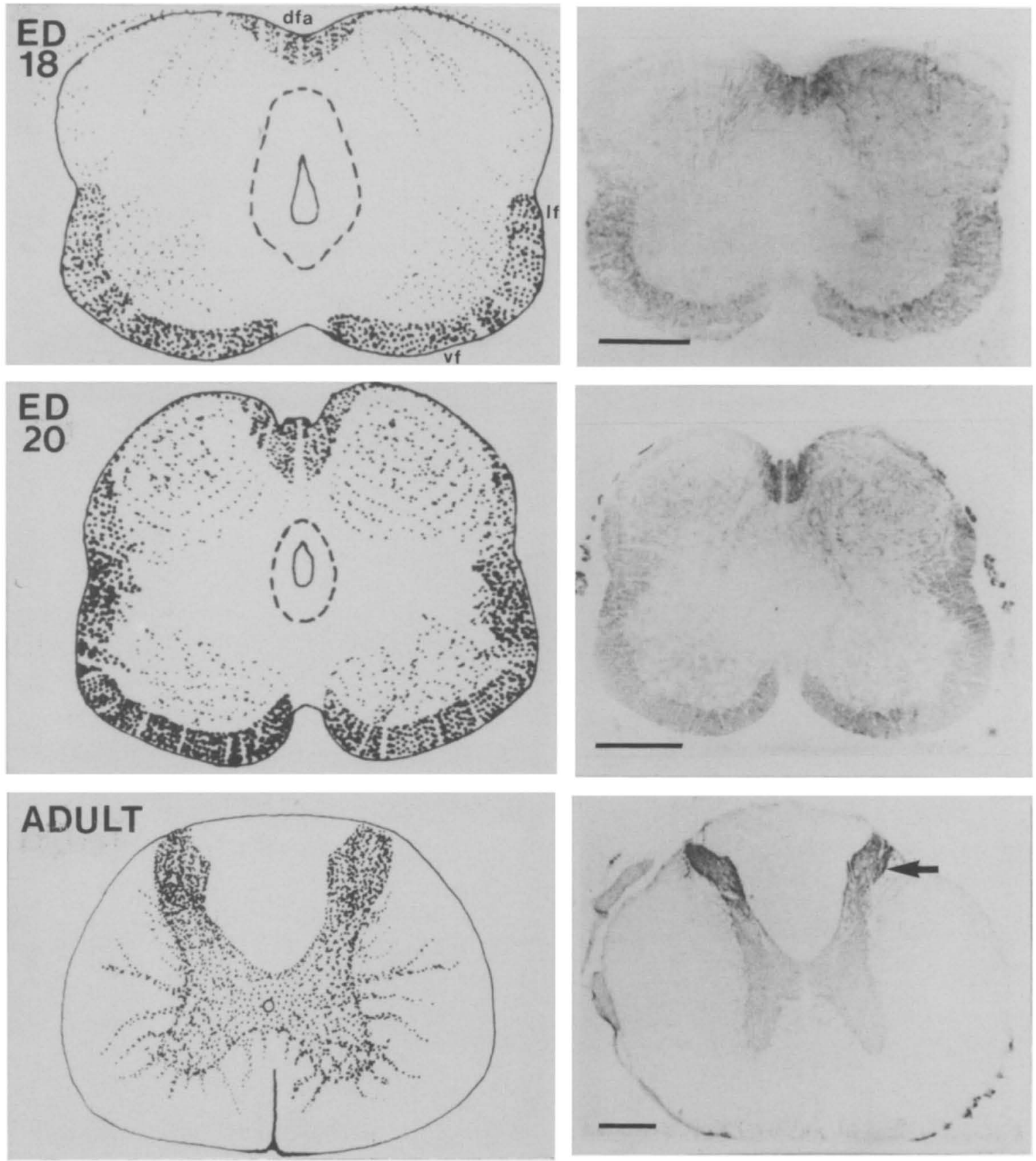

Fig. 5. A summary of the development of synaptophysin immunoreactivity in the prenatal period and in the adult illustrated by graphics and photographs of transverse sections of the spinal cord. (A) ED 12-16. In the dorsal spinal cord, immunoreactivity was particularly seen in the dorsal root entrance zone (dre) at ED 12 (arrowhead), the dorsal root bifurcation zone (drb) at ED 14 (arrowhead), the dorsal funiculus (df) at ED 16 (arrowhead), and at the intrasegmental primary afferent colaterals (ic) at ED 16 (curved arrow) close to the dorsal horn (DH). In the ventral spinal cord, immunoreactivity was particularly seen in the developing marginal layer (ventral funiculus) (ML/vf). Note at ED 14 the staining of the contralaterally projecting nerve fibers (cpf, triangle) and the ipsilaterally projecting cells (ipc, asterisks), which form at ED 15-16 the lateral funiculus (If) of the marginal layer. (B) ED 18-20. In the dorsal spinal cord, immunoreactivity is found in the dorsal funiculus where the ascending zone (dfa) is formed at ED 18 which later becomes the fasciculus gracilis and cuneatus in the upper thoracic segments. In the ventral spinal cord, immunoreactivity is mainly confined to the ventral and lateral funiculus. The ependymal layer was always immunonegative. Adult. Immunoreaction is mainly confined to the gray matter, particularly in the laminae L I-III (arrow) of the dorsal horn (DH). Scale bars in A, B $=20 \mu \mathrm{m}$. 


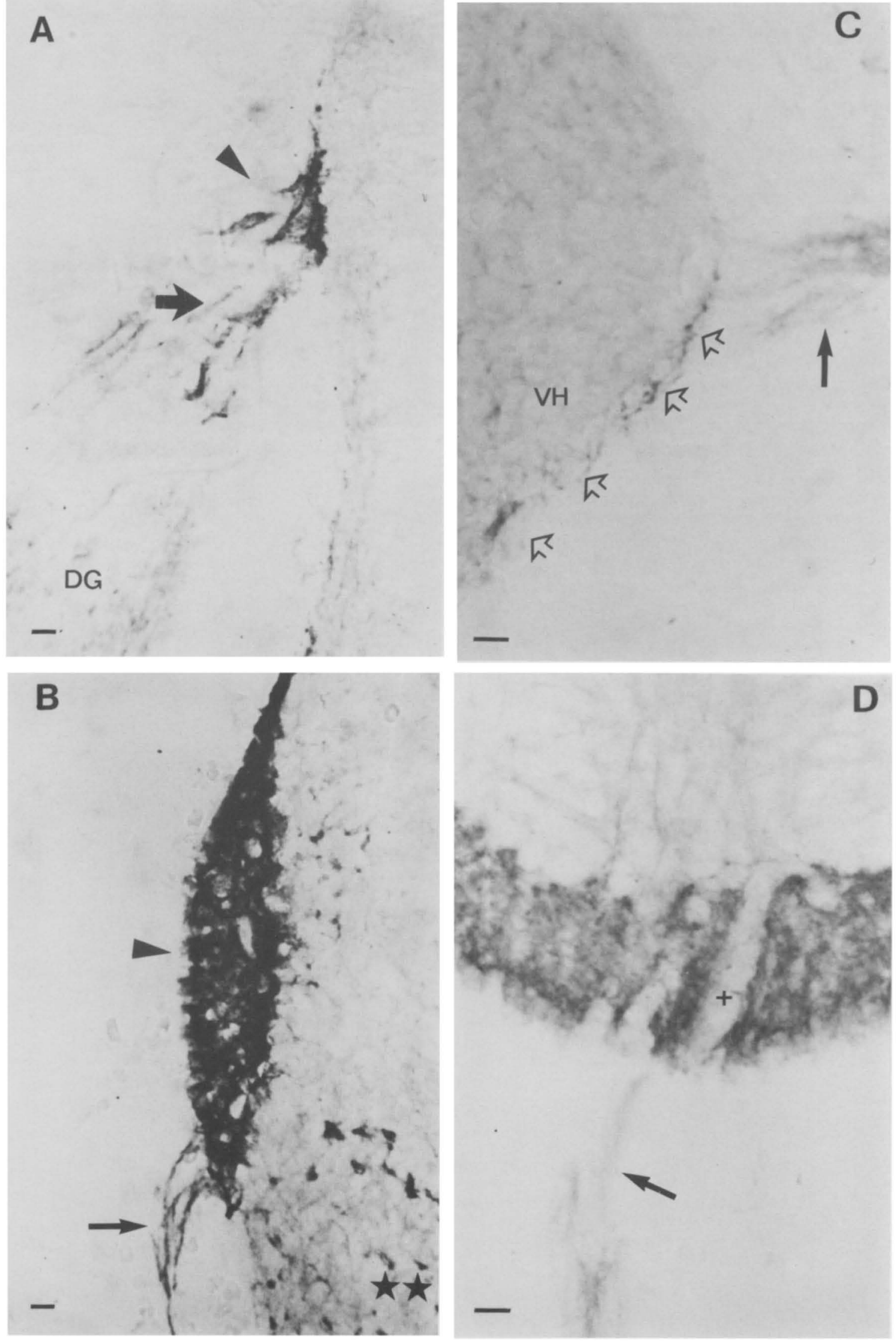

Fig. 6. 


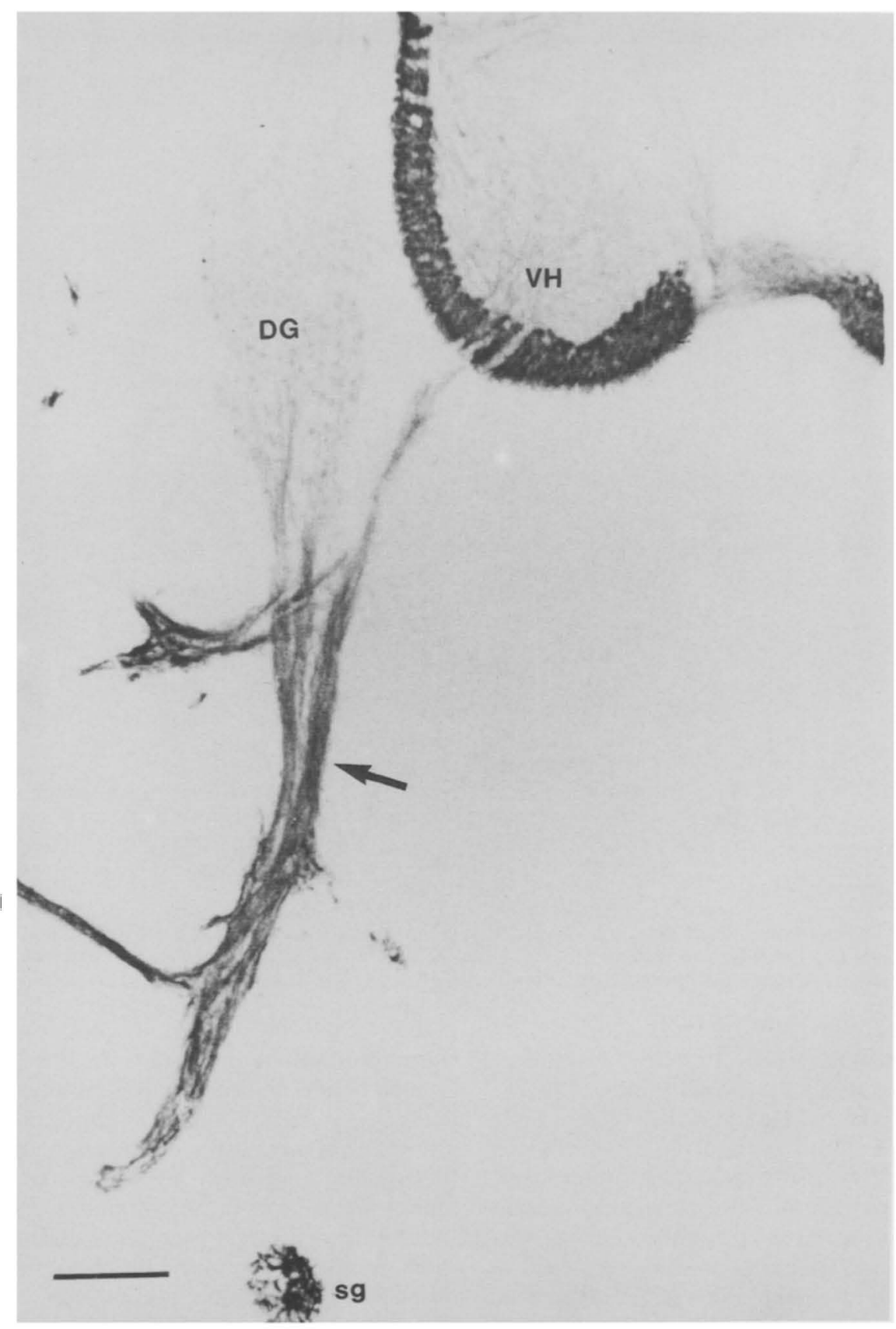

Fig. 7. Immunocytochemical detection of synaptophysin at ED 14. Efferent fibers of the ventral horn (VH) and afferent fibers to the dorsal root ganglion (DG) are strongly stained. Note that the nerve fibers (arrow) are slightly more strongly stained when followed into the periphery. A heavily stained sympathetic ganglion (sg) is shown at the bottom. Scale bar $=10 \mu \mathrm{m}$.

Fig. 6. Immunocytochemical analysis of synaptophysin at ED 12 and 14. Higher magnification of spinal cord transverse sections shown also in Fig. 5. (A) At ED 12, compared to the dorsal root ganglion (DG) an increased level of immunoreactivity was observed in the fibers of the dorsal root (arrow) and in the dorsal root entrance zone (arrowhead). (B) At ED 14, the dorsal root bifurcation zone (arrowhead) shows strong staining. Ipsilateral projecting cells $(\star \star \star)$ ) and dorsal root (arrow) are also stained. (C) At ED 12 a faint staining could be observed in the ventral horn (VH) particularly at its external border (open arrows) and in the ventral root (arrow). (D) At ED 14, the marginal layer (ventral funiculus) exhibits strong staining. Note the faintly stained channels $(+)$ within the marginal layer through which the axons (arrow) of the motor neurons leave the spinal cord. Scale bars in $A-D=1 \mu \mathrm{m}$. 


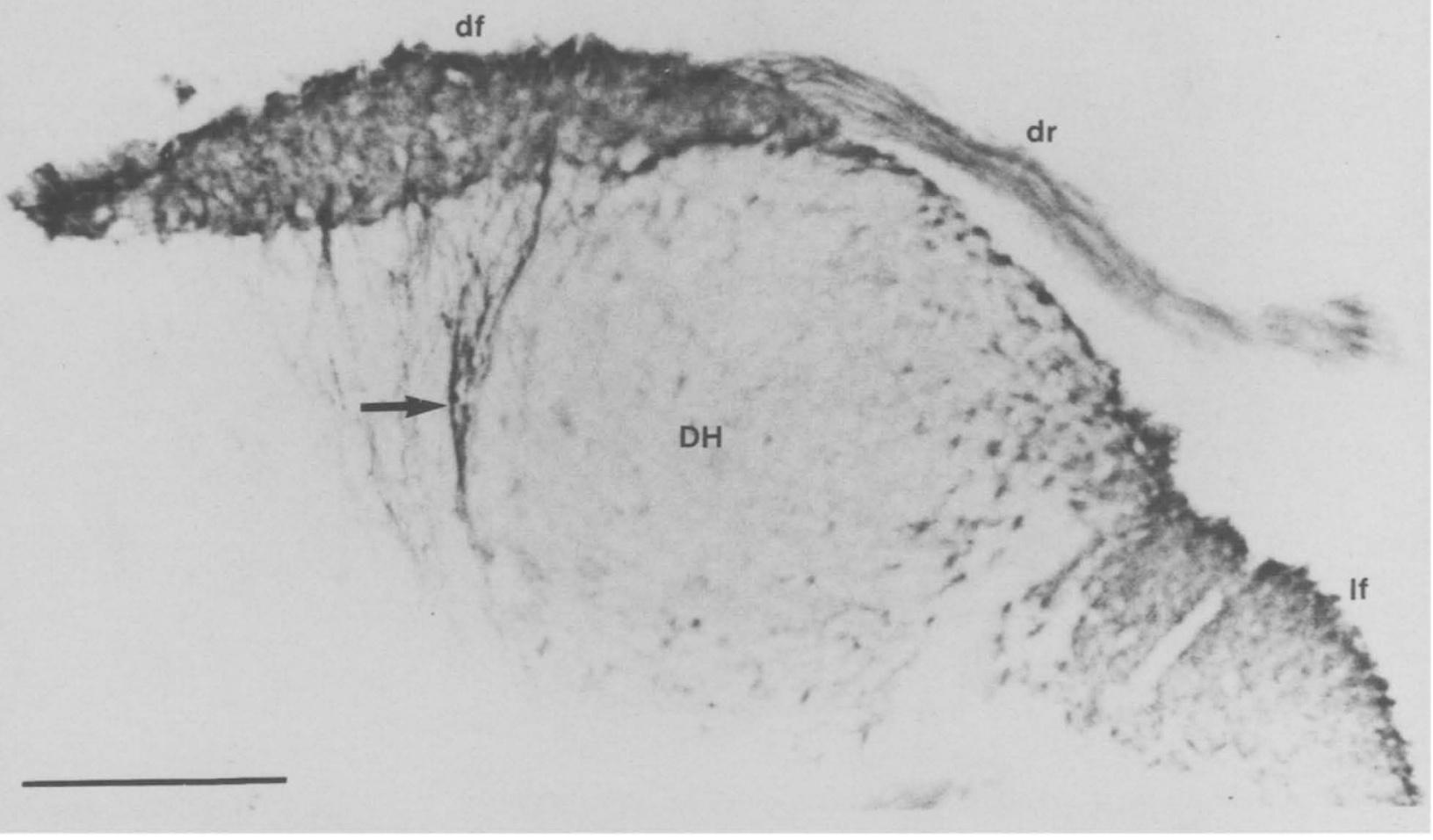

Fig. 8. Immunocytochemical detection of synaptophysin at ED 16. At this stage a separate lateral (1f) and dorsal $(\mathrm{d} f)$ funiculus can be distinguished. Note the staining of the intrasegmental primary afferent colaterals (arrow) from the dorsal funiculus to the dorsal horn (DH). The dorsal root $(\mathrm{dr})$ is also stained. Scale bar $=10 \mu \mathrm{m}$.

neurons as described above) since intersegmental reflex discharges can be elicited around ED $16 .{ }^{28}$ Axodendritic synapses have also been observed electronmicroscopically in rat and mouse at a similar developmental stage within the ventrolateral marginal layer. ${ }^{12,34,37}$ However, functional axodendritic synapses present in the ventrolateral marginal layer do not persist because the intersegmental reflexes gradually disappear during further pre- and postnatal development. ${ }^{28}$ Our results show that this process is paralleled by reduction of synaptophysin immunostaining in the marginal layer in later stages of the prenatal period and during the first week after birth during the formation of the adult white matter (see Ref. 4, Bergmann et al., unpublished observations).

Synaptophysin expression in the afferent fibers of the spinal cord

A parallelism of fiber formation and synaptophysin expression was also observed in this study in the dorsal root ganglia and the sensory afferents. At ED 12 , transcription in the perikarya of the dorsal root ganglia is followed by translation and export of synaptophysin to the dorsal root entrance zone of the spinal cord. Interestingly enough, at ED 14 strong synaptophysin immunoreactivity is observed in the dorsal root bifurcation zone concomitantly with the ventrolateral marginal layer. Indeed, multiple synaptic contacts have been observed in the developing dorsal funiculus of the mouse embryo. ${ }^{36}$

The first synaptophysin-positive collaterals of the primary afferent fibers from the dorsal root ganglion extend to the dorsal horn at ED 16 (see Fig. 8). Thus, in the intermediate layer the first functional synaptic contacts between the afferent and the efferent part of the reflexogenic circuit are formed. These synapses, in contrast to the synaptophysin-rich areas in the marginal layer, are probably permanent because synaptophysin in the gray matter of the dorsal horn is also present in the adult (see also Fig. 5B). Since intrasegmental reflex arcs and reflexogenic movements start around ED 16, 21,28,35 the synaptophysin-positive fibers projecting to the dorsal horn described here immediately become functional.

\section{Comparison with other brain areas}

We found that expression of synaptophysin in the rat spinal cord starts at ED 12 and after ED 14 
reached an almost constant level, which was kept until birth followed by a postnatal rise to reach the adult level. In the cerebral cortex, synaptophysin expression occurs mainly after birth and there it has been reported to be a reliable marker for synaptogenesis. ${ }^{714}$ In contrast, our results are more in agreement with those in other brain areas where synaptophysin expression and synaptogenesis do not occur in a parallel way. For example, in the rat cerebellar cortex, in which synaptophysin expression exhibits a similar postnatal rise as in the cortex, neuronal growth cones express synaptophysin before mature synapses are present. ${ }^{15}$ Also, in the rat retina a synaptic vesicle membrane protein has been observed to be present in the nerve fiber layer before synaptogenesis. $^{29}$

\section{CONCLUSION}

In the developing rat spinal cord, expression of synaptophysin mRNA starts within the neuroepithelium. However, translation to the protein occurs after migration of the neuroblasts to the intermediate layer concomitantly with the outgrowth of nerve fibers. Thus, synaptophysin as a regular constituent of synaptic vesicles can be used as a differentiation marker to monitor both fiber outgrowth and subsequent synapse formation.

Acknowledgements - The authors thank Mrs S. Bucher, M. Rudolf, I. Urban, R. Leder and Mr W. Podschuweit for expert technical assistance, and Mrs B. Mader for typing this manuscript. This work was supported by Landesforschungsschwerpunkt 32 and by Deutsche Forschungsgemeinschaft (Be 1330 and Gr 681).

\section{REFERENCES}

1. Altman J. and Bayer S. A. (1984) The development of the rat spinal cord. Adv. Anat. Embryol. Cell Biol. 85, 1-166.

2. Angulo Y. and González A. W. (1932) The prenatal development of behavior in the albino rat. J. comp. Neurol. 55, $395-442$.

3. Bööj S., Goldstein M., Fischer-Colbrie R. and Dahlström A. (1989) Calcitonin gene-related peptide and chromogranin A: presence and intra-axonal transport in lumbar motor neurons in the rat, a comparison with synaptic vesicle antigens in immunohistochemical studies. Neuroscience 30, 479-501.

4. Cabalka L. M., Ritchie T. C. and Coulter J. D. (1990) Immunolocalization and quantitation of a novel nerve terminal protein in spinal cord development. J. comp. Neurol. 295, 83-91.

5. Chun J. J. M. and Shatz C. J. (1988) Redistribution of synaptic vesicle antigens is correlated with the disappearance of a transient synaptic zone in the developing cerebral cortex. Neuron 1, 297-310.

6. Dennis M. J., Ziskind-Conhaim L. and Harris A. J. (1981) Development of neuromuscular junctions in rat embryos. Devl Biol. 81, 266-279.

7. Devoto S. H. and Barnstable C. J. (1989) Expression of the growth cone specific epitope CDAl and the synaptic vesicle protein SVP 38 in the developing mammalian cerebral cortex. J. comp. Neurol. 290, 154-168.

8. Hsu S. M., Raine L. and Fanger H. (1981) Use of avidin-biotin-peroxidase complex (ABC) in immunoperoxidase techniques: a comparison between $\mathrm{ABC}$ and unlabeled antibody (PAP) procedures. J. Histochem. Cytochem. 29, $577-580$.

9. Jahn R. and De Camilli P. (1991) Membrane proteins of synaptic vesicles: markers for neurons and endocrine cells; tools for the study of neurosecretion. In Markers for Neural and Endocrine Cells. Molecular and Cell Biology, Diagnostic Applications (eds Langley K. and Gratzl M.), pp. 25-92. VCH-Verlagsgesellschaft, Weinheim, F.R.G.

10. Jahn R., Schiebler W., Ouimet C. and Greengard P. (1985) A 38,000 dalton membrane protein (p38) present in synaptic vesicles. Proc. natn. Acad. Sci. U.S.A. 82, 4137-4141.

11. Jahn R., Navone F., Greengard P. and De Camilli P. (1987) Biochemical and immunocytochemical characterization of p38, an integral membrane glycoprotein of small synaptic vesicles. Ann. NY Acad. Sci. 493, 497-499.

12. Kanemitsu A. and Matsuda S. (1984) Synaptogenesis in the chick cervical cord and possible initial central pathways from dorsal root fibers to motor neurons-Golgi and electron microscopic studies. Neurosci. Lett. 48, $1-6$.

13. Kaplan B. B., Bernstein S. L. and Gioio A. E. (1979) An improved method for the rapid isolation of bovine ribonucleic acid. Biochem. J. 183, 181-184.

14. Knaus P., Betz H. and Rehm H. (1986) Expression of synaptophysin during postnatal development of the mouse brain. J. Neurochem. 47, 1302-1304.

15. Leclerc N., Beesley P. W., Brown I., Colonnier M., Gurd J. W., Paladino T. and Mawkes R. (1989) Synaptophysin expression during synaptogenesis in the rat cerebellar cortex. J. comp. Neurol. 280, 197-212.

16. Leube R. E., Kaiser P., Seiter A., Zimbelmann R., Franke W. W., Rehm H., Knaus P., Prior P., Betz H., Reinke H., Beyreuther K. and Wiedenmann B. (1987) Synaptophysin: molecular organization and mRNA expression as determined from cloned cDNA. Eur. molec. Biol. Org. J. 6, 3261-3268.

17. Ley T. J., Anagnou N. P., Pepe G. and Nienhuis A. W. (1982) RNA processing errors in patients with $\beta$-thalassemia. Proc. natn. Acad. Sci. U.S.A. 79, 4775-4779.

18. Lizardi P. M., Binder R. and Short S. A. (1984) Preparative isolation of DNA and biologically active mRNA from diethylaminoethyl membrane. Gene Anal. Techn. 1, 33-39.

19. Lupa M. T. and Hall Z. W. (1989) Progressive restriction of synaptic vesicle protein to the nerve terminal during development of the neuromuscular junction. J. Neurosci. 9, 3937-3945.

20. Mandler R. N., Schaffner A. E., Novotny E. A., Lange G. D., Smith S. V. and Barker J. L. (1990) Electrical and chemical excitability appear one week before birth in the embryonic rat spinal cord. Brain Res. 522, 46-54.

21. Narayanan C. H., Fox M. W. and Hamburger V. (1971) Prenatal development of spontaneous and evoked activity in the rat (Rattus norvegicus albinus). Behavior 40, 100-133.

22. Nornes H. O., Hart H. and Carry M. (1980) Pattern of development of ascending and descending fibers in embryonic spinal cord of chick: I. Role of position information. J. comp. Neurol. 192, 119-132.

23. Nornes H. O., Hart H. and Carry M. (1980) Pattern of development of ascending and descending fibers in embryonic spinal cord of chick: II. A correlation with behavioral studies. J. comp. Neurol. 192, 133-141. 
24. Oppenheim R. W., Shneiderman A., Shimizu I. and Yaginuma H. (1988) Onset and development of intersegmental projections in the chick embryo spinal cord. J. comp. Neurol. 275, 159-180.

25. Phelps P. E., Barber R. P., Brennan L. A., Maines V. M., Salvaterra P. M. and Vaughn J. E. (1990) Embryonic development of four different subsets of cholinergic neurons in rat cervical spinal cord. J. comp. Neurol. 291, 9-26.

26. Ritchie T. C., Thomas M. A. and Coulter J. D. (1989) A nerve terminal protein with a selective distribution in spinal cord and brain. J. Neurosci. 9, 2697-2709.

27. Ruppert C., Goldowith D. and Wille W. (1986) Proto-oncogene c-myc is expressed in cerebellar neurons at different developmental stages. Eur. molec. Biol. Org. J. 5, 1897-1901.

28. Saito K., Ito S., Seno N., Kitazawa T. and Ohga A. (1986) Development of spinal reflexes in the rat fetus. In Development of Plasticity of the Mammalian Spinal Cord (eds Goldberger M. E., Gorio A. and Murray M.). Vol. III, pp. 25-38. Fidia Res. Series. Liviana Press, Padova.

29. Sarthy P. V. and Bacon W. (1986) Developmental expression of a synaptic vesicle-specific protein in the rat retina. Devl Biol. 112, 284-291.

30. Schilling K. and Aletsee-Ufrecht M. C. (1989) An immunoblot assay for the simultaneous quantification of several antigens. Analyt. Biochem. 177, 203-206.

31. Stein R., Mori N., Mathews K., Li-Ching L. and Anderson D. J. (1988) The NGF-inducible SCG10 mRNA encodes a novel membrane-bound protein present in growth cones and abundant in developing neurons. Neuron 1, 463-476.

32. Südhof T. C., Lottspeich F., Greengard P., Mehl E. and Jahn R. (1987) A synaptic vesicle protein with a novel cytoplasmic domain and four transmembrane regions. Science 238, 1142-1144.

33. Thomas L., Hartung K., Langosch D., Rehm H., Bamberg E., Franke W. W. and Betz H. (1988) Identification of synaptophysin as a hexameric channel protein of the synaptic vesicle membrane. Science 242, 1050-1053.

34. Vaughn J. E., Barber R. P. and Sims T. J. (1988) Dendritic development and preferential growth into synaptogenic fields: a quantitative study of Golgi-impregnated spinal motor neurons. Synapse 2, 69-78.

35. Vaughn J. E. and Grieshaber J. A. (1973) A morphological investigation of an early reflex pathway in developing rat spinal cord. J. comp. Neurol. 148, 177-210.

36. Vaughn J. E., Henrikson C. K., Chernow C. R., Grieshaber J. A. and Wimer C. C. (1975) Genetically-associated variations in the development of reflex movements and synaptic junctions within an early reflex pathway of mouse spinal cord. J. comp. Neurol. 161, 541-554.

37. Vaughn J. E., Sims T. and Nakashima M. (1977) A comparison of the early development of axodendritic and axosomatic synapses upon embryonic mouse spinal motor neurons. J. comp. Neurol. 175, 79-100.

38. Xue G. P., Calvert R. A. and Morris R. J. (1990) Expression of the neuronal surface glycoprotein Thy-1 is under post-transcriptional control, and is spatially regulated, in the developing olfactory system. Development 109, 851-864. 